\title{
Keratoconus: an analysis of corneal asymmetry
}

\section{M Burns, F M Johnston, D G Frazer, C Patterson, A J Jackson}

Background: Keratoconus, a non-inflammatory corneal ectasia, is reported to have bilateral involvement in over $90 \%$ of patients. The purpose of this study was to quantify the extent of asymmetry of disease at presentation to a regional corneal clinic.

Methods: Eighty three patients diagnosed at presentation, using a combination of videokeratography, slit lamp examination, and refractive findings were retrospectively selected. On this basis, 73 patients were designated as having evidence of keratoconus in both eyes. In order to quantify the degree of asymmetry between fellow eyes in these bilateral patients, intraclass correlation was calculated for best spectacle corrected visual acuity (BSCVA) and for 13 different topographical indices generated using videokeratography. In order to examine the link between each index and visual function, the intrapatient differences in each index were compared to the intrapatient differences in BSCVA using Pearson's correlation.

Results: BSCVA showed a high degree of asymmetry between fellow eyes with a correlation coefficient of $r=0.006$. With the exception of area analysed, all of the topographical indices also showed disparity between paired eyes $(r=0.01$ to $r=0.25)$. Pearson's analysis found that the intrapatient differences in the standard deviation of the power (SDP), average corneal power (ACP), central corneal power $(K)$, as well as the composite keratoconus prediction index (KPI) inversely correlated with the intrapatient differences in best spectacle corrected acuity $(r=-0.76$, $-0.75,-0.69$, and -0.73 respectively).

Conclusions: This study demonstrates, quantitatively, the asymmetry of disease found in patients at the point of initial diagnosis of keratoconus. It also suggests that increases in indices which reflect various aspects of corneal power as well as the composite index KPI correlate with a decrease in BSCVA.

$\mathrm{K}$ ratoconus is a non-inflammatory disease characterised by progressive corneal thinning and apical protrusion.

Typically, it presents in early adulthood and visual symptoms result from irregular astigmatism and increasing myopia. ${ }^{12}$

Early keratoconus is difficult to detect using clinical tests and videokeratography has proved invaluable when forming a definitive diagnosis. ${ }^{3-5}$ Computerised analysis has developed a range of quantitative indices assessing differing aspects of keratoconic corneal topography (table 1). ${ }^{6-9}$ In order to maximise the diagnostic potential of these descriptors, a multivariate keratoconus prediction index (KPI) was developed following discriminant analysis of SimK1, SimK2, OSI, CSI, DSI, SAI, IAI, and AA. ${ }^{9}$

Although many authors acknowledge the existence of asymmetric involvement, ${ }^{121011}$ to date very few formal comparisons of the extent of asymmetric disease, between fellow eyes, has been undertaken. The aims of this study were to use videokeratographic analysis to quantify the degree of intrapatient asymmetry in bilateral keratoconus and to identify if any of the known indices could be used individually to quantify asymmetry. Secondly, the relation between these indices and the detrimental effect of keratoconus on visual function was investigated and correlated with asymmetry.

\section{METHODS}

\section{Patient selection}

A total of 83 consecutive keratoconus patients referred to the Regional Corneal Clinic, Royal Victoria Hospital between 1997 and 2000 were selected for investigation. Patients with a history of contact lens wear, previous eye surgery, or corneal disease were excluded from the study. Corneal maps had been performed on each patient at presentation using the Topographic Modelling System (TMS-1) (Computed Anatomy Inc, New York, USA). Uncorrected visions and best spectacle corrected visual acuities (BSCVA) had been measured using a conventional internally illuminated Snellen chart. Slit lamp biomicroscopic examination and refractive findings had also been recorded at initial assessment. A diagnosis of keratoconus for each eye had been determined at the time of initial diagnosis by experienced clinicians using the combined results from slit lamp biomicroscopy examination, refraction, and corneal mapping.

A total of 13 different corneal indices comprising K, I-S, SRI, SAI, ACP, CEI, SDP, DSI, OSI, CSI, IAI, AA, and KPI were generated for each corneal map. ${ }^{6} 7912$

\section{Statistical analysis}

A database containing all 13 quantitative indices, as well as BSCVA for each eye, was constructed for all keratoconus patients. In order to quantify the degree of asymmetry between fellow eyes, in the cases where evidence of bilateral disease had been identified, the intraclass correlation (one way random) coefficient between paired eyes was calculated for each quantitative descriptor. The BSCVA of the patients in the bilateral group, denoted as a Snellen decimal, was available for 57 patients. Intrapatient disparity of this parameter was also quantified using intraclass correlation.

Pearson's correlation coefficent was used to determine the degree of correlation between the asymmetry in each index and the asymmetry in BSCVA. In every case, asymmetry was determined by subtracting data relating to the left eye from that for the right eye. Tests of whether coefficients differed significantly from zero were conducted at the 5\% significance level (two tailed). As corneal opacification limits the ability of

Abbreviations: $\mathrm{AA}$, area analysed; $\mathrm{ACP}$, average corneal power BSCVA, best spectacle corrected visual acuity; CEI, corneal eccentricity index; CSI, centre surround index; DSI, differential sector index; IAI, irregular astigmatism index; I-S, inferior-superior dioptric asymmetry; $\mathrm{K}$, central corneal power; $\mathrm{KPI}$, keratoconus prediction index; OSI, opposite sector index; SAl, surface asymmetry index; SDP, standard deviation of the power; SRI, surface regularity index. 
Table 1 Summary of the quantitative indices generated by videokeratography 5813

\begin{tabular}{|c|c|c|}
\hline Index & Description & Normal range \\
\hline K & $\begin{array}{l}\text { Central } \mathrm{K} \text { reading. Calculates the } \\
\text { difference in steepness between the } \\
\text { inferior and superior cornea at a } \\
\text { distance of } 3 \mathrm{~mm} \text { from the apex }\end{array}$ & $\begin{array}{l}<47.2 \mathrm{D} \\
\text { or }>7.2 \mathrm{~mm}\end{array}$ \\
\hline I-S & $\begin{array}{l}\text { The inferior-superior dioptric } \\
\text { asymmetry }\end{array}$ & $<1.4$ \\
\hline $\mathrm{ACP}$ & Average corneal power & 40.5 to $46.7 \mathrm{D}$ \\
\hline CEI & $\begin{array}{l}\text { Corneal eccentricity index or } \\
\text { global shape factor. Positive } \\
\text { for a prolate surface and negative } \\
\text { for an oblate surface }\end{array}$ & $\begin{array}{l}-0.114 \text { to } \\
0.806\end{array}$ \\
\hline SDP & $\begin{array}{l}\text { Standard deviation of the power. } \\
\text { Increased when there is a wide } \\
\text { range of dioptric power within } \\
\text { the cornea }\end{array}$ & 0.37 to 1.33 \\
\hline DSI & $\begin{array}{l}\text { Differential sector index. Reports } \\
\text { the greatest difference in average } \\
\text { power between any two sectors }\end{array}$ & 0.21 to 3.51 \\
\hline OSI & $\begin{array}{l}\text { Opposite sector index. Represents } \\
\text { the greatest difference of average } \\
\text { power in opposite sectors }\end{array}$ & -0.55 to 2.09 \\
\hline CSI & $\begin{array}{l}\text { Centre surround index. The difference } \\
\text { in the average area corrected corneal } \\
\text { power between the central corneal } \\
\text { zone } 3 \mathrm{~mm} \text { in diameter and a } 3 \mathrm{~mm} \\
\text { annulus surrounding the central area }\end{array}$ & -0.28 to 0.80 \\
\hline$|A|$ & $\begin{array}{l}\text { Irregular astigmatism index. Reports } \\
\text { the average inter-ring variation in } \\
\text { power along semi-meridians }\end{array}$ & 0.19 to 0.49 \\
\hline AA & $\begin{array}{l}\text { Area analysed. The ratio of the } \\
\text { area used for calculation compared } \\
\text { to that covered by image of the } \\
\text { concentric rings }\end{array}$ & 0.70 to 0.94 \\
\hline SAl & $\begin{array}{l}\text { Surface asymmetry index. Detects } \\
\text { alteration of corneal symmetry- } \\
\text { for example, off centre keratoconus } \\
\text { apices by comparing areas of the } \\
\text { cornea } 180^{\circ} \text { apart }\end{array}$ & 0.10 to 0.42 \\
\hline SRI & $\begin{array}{l}\text { Surface regularity index. Values can } \\
\text { be used to predict the optical outcome } \\
\text { that might be expected based on } \\
\text { corneal topography }\end{array}$ & 0.0 to 0.56 \\
\hline
\end{tabular}

the cornea to refract light irrespective of the corneal curvature and regularity, seven patients with apical corneal scarring in at least one eye were excluded from this analysis. All the statistical analysis was performed using SPSS version 9.0.for Windows (SPSS Inc, Chicago, IL, USA).

\section{RESULTS}

Of the 83 patients with keratoconus, 10 individuals were excluded on the grounds that no clinical or videokeratographic signs of keratoconus could be detected in the fellow eye. These patients were designated as having unilateral keratoconus and were excluded from the analysis of corneal asymmetry. The remaining 73 patients had a mean age of 27.3 (SD 10.6) years (range of 12-65 years). Appraisal of the topographical maps for the paired eyes found that $81 \%$ of patients had bilateral inferior oval cones. The remaining patients were designated as having mixed cone types, with seven patients having oval cones in both eyes but in different positions and seven patients having a nipple cone in one eye and an oval cone in the other eye.

The mean (SD) values for BSCVA and for each of the indices in patients with bilateral keratoconus are shown in table 2. All of the indices except ACP, I-S, and CEI show a mean value which is outside the normal range quoted by other workers (table 1). ${ }^{9}$ The figures calculated for the range and standard deviation of these indices illustrate the wide variation in these quantitative descriptors in keratoconus patients at initial presentation. Comparison of the data, between right and left eyes shows very little divergence in terms of mean, range, or standard deviation.

The intraclass correlation between paired eyes for BSCVA and for each of the corneal indices in patients designated as having bilateral keratoconus is shown in table 2. The correlation coefficient of $r=0.006$ for BSCVA between paired eyes indicates a high degree of disparity in paired eyes at presentation (fig 1A). With the exception of AA there is also a poor correlation, and therefore a high level of disparity, between paired eyes for all of the indices tested (table 2). Notably, the intraclass correlation coefficient for BSCVA was among the lowest observed. The composite index KPI was also a relatively good indicator of intrapatient asymmetry (fig 1B) but it was not markedly better than any of the individual indices (CSI, OSI, DSI, SAI) which are used to calculate this composite indicator.

Using Pearson's correlation, the link between index asymmetry and asymmetry of visual acuity was evaluated (table 3). If abnormal or raised values of an individual index predicted a fall in visual function then a strong inverse correlation would be found. The SDP, ACP, and K indices, which are various descriptors of corneal power, all show a strong inverse correlation with BSCVA with correlation coefficients of $r=-0.76(p=0.01), r=-0.75 \quad(p=0.01)$, and $r=-0.69(\mathrm{p}=0.01)$ respectively. Figure $2 \mathrm{~A}$ shows the inverse relation between SDP and BSCVA differences in the paired eyes. The composite index KPI is also a good predictor of BSCVA ( $r=-0.73, \mathrm{p}=0.01$; fig 2B). Notably, CSI and SRI proved to be poor predictors of BSCVA despite being good measures of asymmetry.

\section{DISCUSSION}

In this study, we have used the precision and sensitivity of videokeratography to measure the degree of asymmetry of the disease in paired eyes of patients at first presentation to a hospital based specialist corneal clinic.

The quantification of asymmetry has important patient management implications. Successful RGP contact lens fitting requires good patient motivation, which is much less likely in asymmetric disease with good spectacle corrected visual acuity in the least affected eye. ${ }^{13}$ Similarly, decisions regarding penetrating keratoplasty will be influenced by good corrected visual acuity in the fellow eye.

The intrapatient asymmetry of keratoconus at presentation is confirmed in our study by the poor intraclass correlation between paired eyes for spectacle corrected visual acuity $(r=0.006)$. All of the corneal indices assessed, except AA, confirmed the presence of asymmetry. SRI $(r=0.0 .01)$, CSI $(r=0.03)$, and SDP $(r=0.03)$ proved to be the best markers for intrapatient asymmetry.

The variable ability of these topographical indices to predict asymmetry between paired eyes is likely to be due to the fact that each assesses different corneal characteristics. A maximally increased CSI reading will be found with steep central cones and a moderately raised value with large decentred cones, whereas the DSI, OSI, and I-S indices produce maximum values with decentred cones and reduced measurements with central cones. ${ }^{6}$ In this and other studies, the majority of cones were of the inferior oval type. ${ }^{11}{ }^{114}$ The reason that CSI proved to be a better measure of asymmetry between paired eyes than DSI, OSI, and I-S is unclear at present. Maguire and Bourne, (1989) found that the apex of inferiorly displaced cones were found 1.3 and $2.5 \mathrm{~mm}$ from the visual axis. ${ }^{3}$ This is within the central $3 \mathrm{~mm}$ annulus used for calculating the CSI index and would cause a higher value. However, we did not specifically quantify the magnitude and direction of cone apex displacement in our study. 
Table 2 Intraclass correlation coefficient between paired eyes calculated for best corrected visual acuity (Snellen decimal equivalent) and for each topographical index

\begin{tabular}{|c|c|c|c|c|c|}
\hline \multirow[b]{2}{*}{ Index } & \multicolumn{2}{|l|}{ Right eye } & \multicolumn{2}{|l|}{ Left eye } & \multirow{2}{*}{$\begin{array}{l}\text { Intraclass } \\
\text { correlation } \\
\text { coefficient }\end{array}$} \\
\hline & Mean (SD) & Range & Mean (SD) & Range & \\
\hline $\begin{array}{l}\text { Best spectacle } \\
\text { corrected VA } \\
\text { (Snellen decimal) }\end{array}$ & $0.69(0.34)$ & 0.00 to 1.20 & $0.63(0.37)$ & 0.001 to 1.20 & 0.006 \\
\hline $\begin{array}{l}\text { Surface regularity } \\
\text { index (SRI) }\end{array}$ & $1.24(0.83)$ & 0.10 to 4.59 & $1.24(0.82)$ & 0.02 to 4.02 & 0.01 \\
\hline $\begin{array}{l}\text { Standard deviation } \\
\text { of power (SDP) }\end{array}$ & $3.80(2.34)$ & 0.66 to 10.45 & $4.17(2.59)$ & 0.84 to 11.45 & 0.03 \\
\hline $\begin{array}{l}\text { Centre surround } \\
\text { index (CSI) }\end{array}$ & $1.51(2.26)$ & -1.66 to 7.84 & $1.55(2.81)$ & -5.56 to 10.30 & 0.03 \\
\hline $\begin{array}{l}\text { Surface asymmetry } \\
\text { index (SAI) }\end{array}$ & $2.26(1.84)$ & 0.25 to 9.45 & $2.45(1.67)$ & 0.18 to 7.10 & 0.05 \\
\hline $\begin{array}{l}\text { Differential sector } \\
\text { index (DSI) }\end{array}$ & $8.30(4.69)$ & 1.01 to 21.08 & $9.21(5.51)$ & 1.84 to 22.94 & 0.13 \\
\hline $\begin{array}{l}\text { Irregular astigmatism } \\
\text { index (IAI) }\end{array}$ & $0.45(0.19)$ & 0.20 to 1.26 & $0.47(0.22)$ & 0.23 to 1.38 & 0.14 \\
\hline $\begin{array}{l}\text { Central corneal } \\
\text { power (K) }\end{array}$ & $46.79(4.54)$ & 40.00 to 57.31 & $46.94(4.96)$ & 38.69 to 58.84 & 0.16 \\
\hline $\begin{array}{l}\text { Keratoconus predictor } \\
\text { index (KPI) }\end{array}$ & $49.63(41.20)$ & 0 to 100.00 & $53.24(41.31)$ & 0.00 to 100.00 & 0.18 \\
\hline $\begin{array}{l}\text { Average corneal } \\
\text { power (ACP) }\end{array}$ & $45.86(3.76)$ & 33.39 to 54.73 & $46.18(4.26)$ & 39.95 to 57.50 & 0.18 \\
\hline $\begin{array}{l}\text { Inferior minus superior } \\
\text { power (I-S) }\end{array}$ & $5.74(5.04)$ & -9.03 to 17.05 & $6.39(4.83)$ & -4.12 to 18.17 & 0.18 \\
\hline $\begin{array}{l}\text { Opposite sector } \\
\text { index (OSI) }\end{array}$ & $7.11(4.96)$ & 0.15 to 21.08 & $7.80(5.52)$ & 0.10 to 22.94 & 0.22 \\
\hline $\begin{array}{l}\text { Corneal eccentricity } \\
\text { index (CEI) }\end{array}$ & $-0.34(0.63)$ & -0.96 to 0.95 & $-0.28(0.69)$ & -0.96 to 0.96 & 0.25 \\
\hline Area analysed (AA) & $0.66(0.14)$ & 0.24 to 0.86 & $0.66(0.15)$ & 0.23 to 0.89 & 0.38 \\
\hline
\end{tabular}

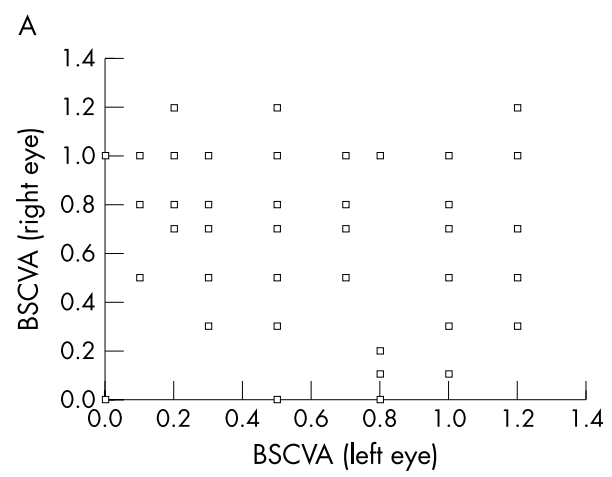

B

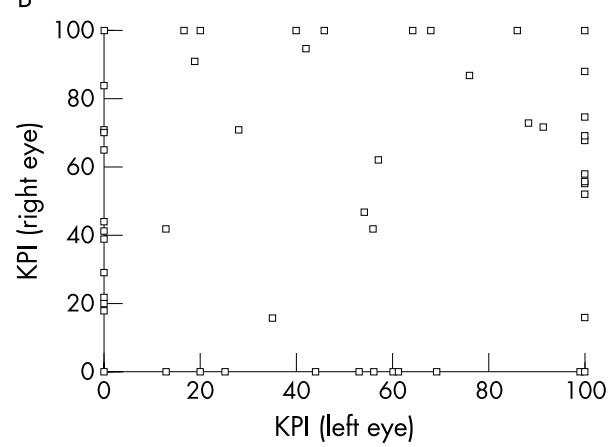

Figure 1 Scatter plot showing the variation between paired eyes in patients with bilateral keratoconus. (A) Best spectacle corrected visual acuity. Intraclass correlation $r=0.006(n=57)$. Data points represent the Snellen decimal equivalent recorded for each eye at presentation. (B) Composite index KPI. Intraclass correlation $r=0.18(n=73)$. Data points represent the indices generated by computerised analysis of corneal mapping performed at presentation.
A

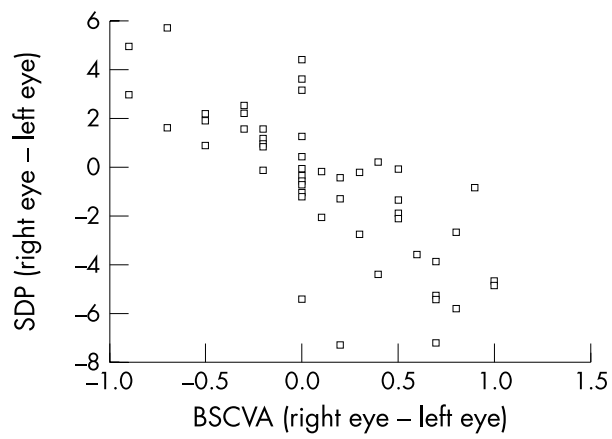

B

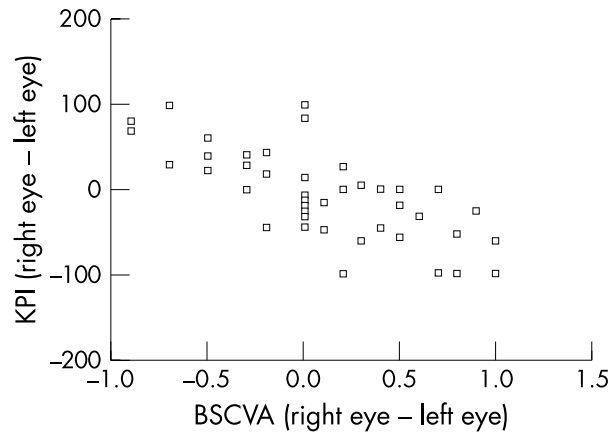

Figure 2 Scatter plot showing the inverse correlation between $(A)$ the intrapatient differences in SDP and the intrapatient differences in best spectacle corrected visual acuity (BSCVA) (Snellen decimal equivalent) in patients with bilateral keratoconus $r=-0.76 p=0.01(n=50)$, and (B) the intrapatient differences in KPI and the intrapatient differences in (BSCVA) (Snellen decimal equivalent) in patients with bilateral keratoconus $r=-0.73 ; p=0.01(n=50)$. Patients with apical corneal scarring in either eye were excluded from the analysis. Coefficients were evaluated using data collected from patients at presentation. 
Table 3 Pearson's correlation coefficient between the intrapatient differences for each index with the intrapatient differences in spectacle corrected visual acuity $(n=50)$

\begin{tabular}{ll}
\hline Index & Pearson's correlation \\
\hline Standard deviation of power (SDP) & $-0.76^{* *}$ \\
Average corneal power (ACP) & $-0.75^{* *}$ \\
Keratoconus prediction index (KPI) & $-0.73^{* *}$ \\
Central corneal power (K) & $-0.69^{* *}$ \\
Differential sector index (DSI) & $-0.6^{* *}$ \\
Inferior minus superior power (I-S) & $-0.67^{* *}$ \\
Opposite sector index (OSI) & $-0.64^{* *}$ \\
Surface regularity index (SRI) & $-0.57^{* *}$ \\
Surface asymmetry index (SAl) & $-0.57^{* *}$ \\
Irregular astigmatism index (IAI) & $-0.51^{* *}$ \\
Centre surround index (CSI) & $-0.50^{* *}$ \\
Corneal eccentricity index (CEI) & $-0.36^{*}$ \\
Area analysed (AA) & 0.21
\end{tabular}

Coefficients were calculated using data collected from patients designated as having bilateral keratoconus. Patients with apical corneal scarring in either eye were excluded from the analysis. Significance is denoted by ${ }^{*} p=0.05$ and ${ }^{* *} p=0.01$.

The SDP index reflects the variation in area corrected corneal power. ${ }^{12}$ It is not influenced by the apical location and appears to be a sensitive measure of corneal asymmetry. The SRI and IAI both reflect local fluctuations in corneal power, which is reported to be a characteristic of moderate to severe keratoconus. ${ }^{912}$ It is likely, therefore, that these two indices show poor intrapatient correlation in asymmetric disease because they reflect keratoconus progression. ${ }^{8}$

The SAI will not be increased by regular astigmatism or centrally located cones but will detect irregular astigmatism and decentred cones. ${ }^{8}$ This value will increase as the irregular astigmatism increases or the decentred cone becomes steeper. Consequently, it should act as a disease progression marker, as confirmed by the poor SAI correlation between paired eyes in this study $(r=0.05)$.

The KPI value is a composite calculation and it might be expected to be a more sensitive indicator of corneal asymmetry. This was not the case in this study and several individual indices showed greater disparity between paired eyes. An explanation may lie in the purpose of the index, which is to give a measure of certainty of diagnosis. ${ }^{9}$ The KPI ranges from $0-100 \%$, indicating the degree of certainty of detection of keratoconus ${ }^{9}$ with moderate to severe cones receiving a KPI score of $100 \%$. Smolek and Klyce ${ }^{15}$ have noted the inability of KPI to distinguish between moderate and severe keratoconus, so its role in illustrating the degree of asymmetric disease may be limited.

Many KPI values were clustered around the $0 \%$ value suggesting an unaffected eye-that is, unilateral keratoconus. The criteria for bilaterality in our study, however, also considered clinical examination, refractive findings, and the topographical map. Thus, many corneas, which gave KPI indices of $0 \%$ exhibited other signs of keratoconus.

An inverse correlation between the intrapatient difference for a particular index and the intrapatient difference in corrected acuities would suggest that progressive visual loss in keratoconus is a direct result of specific changes in corneal topography. The rank order of indices for which the intrapatient difference predicted impaired visual acuity was different from the order with which they predicted asymmetry. The strongest predictor of visual impairment was the SDP descriptor $(r=-0.76 ; \mathrm{p}=0.01)$, which provides a measure of the range in corneal power. ${ }^{9}$ Other measures of corneal power such as ACP $(r=-0.75 ; \mathrm{p}=0.01)$ and $\mathrm{K}$ $(r=-0.69 ; \mathrm{p}=0.01)$ also showed a strong inverse correlation. The I-S descriptor which depicts off centre cones ${ }^{7}$ also demonstrated a good inverse correlation $(r=-0.43$; $\mathrm{p}=0.01)$. These results would suggest that the overall power and cone protrusion reduced the efficacy of the spectacle correction irrespective of cone location.

In conclusion, this study formally demonstrates the degree of asymmetry of disease at presentation of keratoconus patients, both for corneal shape and visual acuity. Quantitative topographical indices reflecting changes in corneal power correlated best with impaired acuity.

\section{Authors' affiliations}

D M Burns, F M Johnston, A J Jackson, Department of Optometry, University of Ulster, Coleraine, Co Londonderry, UK

D M Burns, D G Frazer, A J Jackson, Department of Ophthalmology, Royal Victoria Hospital Belfast, Belfast, UK

C Patterson, Department of Epidemiology and Public Health, Queen's University, Belfast, UK

A J Jackson, Department of Ophthalmology, Queen's University, Belfast, UK

Correspondence to: $\operatorname{Dr} D$ M Burns, Department of Ophthalmology, Royal Victoria Hospital Belfast, Grosvenor Road, Belfast BT12 6BA, UK; dm.burns@ukgateway.net

Accepted 5 March 2004

\section{REFERENCES}

1 Krachmer JH, Eagle RC, Belin MW. Keratoconus and related noninflammatory corneal thinning disorders. Surv Ophthalmol 1984:28:293-322.

2 Rabinowitz YS, Keratoconus. Survey Ophthalmol 1998;42:297-319

3 Maguire L, Bourne WM. Corneal topography of early keratoconus. Am J Ophthalmol 1989;108:107-12.

4 Rabinowitz YS, Nesburn AB, McDonnell PJ. Videokeratography of the fellow eye in unilateral keratoconus. Ophthalmol 1993;100:181-6.

5 Holland DR, Maeda N, Hannush SB, et al. Unilateral keratoconus-incidence and quantitative topographic analysis. Ophthalmol 1997;104:1409-13.

6 Rabinowitz YS, McDonnell PJ. Computer-assisted corneal topography in keratoconus. Refract Corneal Surg 1989;6:400-8.

7 Dingeldein SA, Klyce SD, Wilson SE. Quantative descriptors of corneal shape derived from computer-assisted analysis of photokeratographs. Refract Corneal Surg 1989;5:372-8.

8 Wilson SE, Klyce SD. Advances in the analysis of corneal topography. Sury Ophthalmol 1991;35:269-77.

9 Maeda N, Klyce SD, Smolek MK, et al. Automated keratoconus screening with corneal topography analysis. Invest Ophthalmol Vis Sci 1994;35:2749-57.

10 Cox SN. Management of Keratoconus. J Br Contact Assoc 1984;7:86-92.

11 Owens H, Watters GA. An evaluation of the keratoconic cornea using computerised corneal mapping and ultrasonic measurements of corneal thickness. Ophthal Physiol Opt 1996;16:115-23

12 Maeda N, Klyce SD, Smolek MK. Neural network classification of corneal topography. Invest Ophthalmol Vis Sci 1995;36:1327-35.

13 Woodward EG. Contact lenses in abnormal ocular conditions. In: Philips AJ, Speedwell L, eds. Contact Lenses. Oxford: Butterworth-Heinman, 1997.

14 McMahon TT, Robin JB, Scarpulla KM, et al. The spectrum of topography found in keratoconus. CLAO 1991;17:198-204.

15 Smolek MK, Klyce SD. Current keratoconus detection methods compared with a neural network approach. Invest Ophthalmol Vis Sci 1997;38:2290-9. 